\title{
Effects of Systemic and Local Interferon Beta-1a on Epidural Fibrosis
}

\author{
Mevlüt Özgür Taşkapılıŏlu ${ }^{1}$, Semra Işı ${ }^{1}$, Şeref Doğan ${ }^{1}$, \\ Gonca Özgün ${ }^{2}$, Gökhan Ocakoğlu ${ }^{3}$, Nesrin Uğraş ${ }^{2}$ \\ ${ }^{I}$ Department of Neurosurgery, Uludag University Medical School, Bursa, Turkey \\ ${ }^{2}$ Department of Pathology, Uludag University Medical School, Bursa, Turkey \\ ${ }^{3}$ Department of Biostatistics, Uludag University Medical School, Bursa, Turkey
}

\begin{abstract}
Study Design: Level 1 randomized controlled study.
Purpose: To investigate the effects of systemic and local interferon-beta-1a (IFN- $\beta$-1a) on prevention of epidural fibrosis using histopathological parameters.

Overview of Literature: Epidural fibrosis involves fibroblastic invasion of nerve roots into the epidural space. Formation of dense fibrous tissue causes lumbar and radicular pain. Many surgical techniques and several materials have been proposed in the literature, but no study has assessed the effect of IFN- $\beta$-1a on prevention of epidural fibrosis.

Methods: Forty-eight adult female Sprague-Dawley rats were divided into six groups of eight: sham group, control group, systemic $44 \mu \mathrm{g}$ IFN- $\beta$-1a group and $22 \mu \mathrm{g}$ IFN- $\beta$-1a group (after laminectomy and discectomy, $0.28 \mathrm{~mL}$ and $0.14 \mathrm{~mL}$ IFN- $\beta$-1a applied subcutaneously three times for a week, respectively), local $44 \mu \mathrm{g}$ IFN- $\beta$-1a group (laminectomy and discectomy, followed by $0.28 \mathrm{~mL}$ IFN- $\beta$-1a on the surgical area), and local $22 \mu \mathrm{g}$ IFN- $\beta$-1a group (laminectomy and discectomy, followed by $0.14 \mathrm{~mL}$ IFN- $\beta$-1a on the surgical area). All rats were sacrificed after 4 weeks and groups were evaluated histopathologically.

Results: Compared with sham and control groups, significantly less epidural fibrosis, dural adhesion, and fibroblast cell density were observed in the local and systemic $44 \mu \mathrm{g}$ IFN- $\beta$-1a groups. No other differences were evident between the local and systemic groups. Conclusions: IFN- $\beta$-1a is effective in preventing epidural fibrosis with systemic and local application.
\end{abstract}

Keywords: Fibrosis; Interferon beta-1a; Laminectomy

\section{Introduction}

Failed-back syndrome develops in $20 \%$ of the surgically treated lumbar disc herniation patients [1]. Epidural fibrosis is one of the main factors in failed-back syndrome [1]. Many surgical techniques and several materials have been proposed in various experimental research models to prevent epidural fibrosis. These materials free or pedicle fat graft [2], dermis [3], ligamantum flavum [4], dura mater [5], amniotic membrane [6], gelatin foam sponge [7], microfibrillar collagen [7], hemostatic agents [8,9], carboxymethylcellulose [10-12], polyethylene oxide $[10,12]$, sodium hyaluronan $[9,13]$, topical high-molecular-weight hyaluronan [9,13-15], methylprednisolone, triamcinolone, prednisolone, dexamethasone [16-19], anti-inflammatory agents $[7,16], \mathrm{CO}_{2}$ laser [20], and low-dose external beam

\footnotetext{
Received Sep 17, 2015; Accepted Oct 9, 2015

Corresponding author: Mevlüt Özgür Taşkapılığlu

Department of Neurosurgery, Uludag University Medical Schoo,l Görükle, 16059 Nilüfer/Bursa, Turkey

Tel: +90-224-295-2740, Fax: +90-224-295-0019, E-mail: ozgurt@uludag.edu.tr
} 
radiation [21].

Interferon-beta-1a (IFN- $\beta$-1a) is an approved treatment for multiple sclerosis (MS). It improves the disease course by reducing the relapse rate as well as the persistent neurological deficits. The immunomodulatory effects of IFN$\beta$-1a are well characterized in MS and experimental autoimmune encephalomyelitis (EAE) [22]. IFN- $\beta$-1a reduces the proliferation and cytokine secretion of autoimmune T-cells and decreases blood-brain barrier permeability [22]. This diminishes inflammatory infiltration within the central nervous system (CNS) [22].

Although IFN- $\beta$-1a has been commonly used in MS, there has been no study on the use of IFN- $\beta$ - 1 a in spinal surgery. The aim of our study was to elucidate whether IFN- $\beta$-1a can prevent postoperative adhesions and epidural fibrosis formation.

\section{Materials and Methods}

\section{Surgical procedure}

Forty-eight, 12-week-old, 250-300 g body weight, white Sprague-Dawley rats were used. The care and use of the rats was approved by the Ethical Committee of Animal Resources (September 25th, 2012; 2012-11/04).

For prophylaxis, a single dose of $20 \mathrm{mg} / \mathrm{kg}$ cephasoline sodium (Cefozin, Bilim İlaç, Istanbul-Turkey) was injected intraperitoneally 30 minutes prior to the operation. Intramuscular anesthesia was induced with $70 \mathrm{mg} / \mathrm{kg}$ ketamine hydrochloride (Ketalar, Parke-Davis, Eczacıbaşı, Istanbul, Turkey) and $10 \mathrm{mg} / \mathrm{kg}$ xylazine hydrochloride (Rompun, Bayer, Istanbul, Turkey). The rats were fixed in the prone position and the surgical field was prepared by scrubbing with $4 \%$ chlorhexidine soap (Klorheksol Scrub, Drogsan Pahrmaceuticals, Ankara, Turkey) for 8 minutes and disinfecting with povidone iodine solution (Isosol, Merkez Lab., Istanbul, Turkey). The operation area was covered with sterile blankets and draped. A midline skin incision was made to expose the spinose processes from L4 to L7, and the L5-6 level was determined. Bilateral paraspinous muscles were dissected. A dorsal total laminectomy at the lumbar 5-6 level was performed using an Opmi I operative microscope (Carl Zeiss, Jena, Germany) with a Micromot 50/E drill (Proxxon, Föhren, Germany). After exposing the posterolateral aspect of the right L5-L6 disc a 22-gauge needle was inserted to create a disc injury. In the sham group, laminectomy and disc injury were performed and no treatment was used. In the control group, laminectomy and disc injury were performed and $0.1 \mathrm{~mL}$ of saline was applied to the epidural space. In the systemic $44 \mu \mathrm{g}$ IFN- $\beta$-1a group $\left(S_{44}\right)$, nothing was applied to the epidural space, however $0.28 \mathrm{~mL}$ of IFN- $\beta$-1a was applied subcutaneously (sc) three times for a week. In the systemic $22 \mu \mathrm{g}$ IFN- $\beta$-1a group $\left(S_{22}\right), 0.14 \mathrm{ml}$ of IFN- $\beta$ - 1 a was applied sc three times for a week after the surgical procedure. In the local $44 \mu \mathrm{g}$ IFN- $\beta$-1a group $\left(\mathrm{L}_{44}\right), 0.28 \mathrm{ml}$ of IFN- $\beta$ - 1 a was applied to the epidural space, covering the laminectomy defects. In the local $22 \mu \mathrm{g}$ IFN- $\beta$-1a group $\left(\mathrm{L}_{22}\right), 0.14 \mathrm{~mL}$ of IFN- $\beta-1$ a was applied to the surgical area. The wounds were closed in layers in a routine manner after hemostasis control. After the procedure all rats were housed individually at normal room temperature and were monitored closely using the Basso Beattie Bresnahan (BBB) scale to grade histological and locomotor outcomes [23,24].

\section{Preparation of specimens}

Four weeks after surgery, all rats were sacrificed by the intraperitoneal administration of a high dose (75-100 $\mathrm{mg} / \mathrm{kg}$ ) of tiopental sodium (Pentothal Sodium, Abbott, Roma, Italy). The spinal column was removed en bloc between the L1 to L7 level. The specimens were fixed in $10 \%$ buffered formaldehyde solution. After 2 days for decalcification, they were immersed in Decal solution comprising equal volumes of $10 \%$ formic acid and $8 \%$ $\mathrm{HCl}$ for 3 days. After decalcification, the specimens were cut down to the laminectomy site transverse to the spinal cord, with a thickness of $2 \mathrm{~mm}$. The tissues were routinely processed. Serial sections $3 \mu \mathrm{m}$ in thickness were obtained from paraffin blocks using a model RM 2145 microtome (Leica, Wetzlar, Germany). Sections were stained with haematoxylin-eosin and Masson-Trichrome. Any animal with an intraoperative dural tear, nerve root injury, or postoperative infection and/or hematoma was excluded.

\section{Histopathological examination}

All tissue samples were evaluated by two blinded experienced histopathologists. Upon light-microscopy examination, samples were scored for extent of fibrosis, dural adhesion, foreign-body reaction, granulation tissue, inflammation, medulla spinalis retraction, and density of fibroblasts. The dural adhesion parameters were evaluated according to previously established criteria [18]. Epidural 
fibrosis extention, foreign-body reaction, granulation tissue, inflammation, and medulla spinalis retraction were evaluated according to the established criteria [25]. Fibroblast cell density was calculated in each field at $\times 400$ magnification according to a previously detailed classification [26] (Fig. 1).

\section{Statistical analysis}

Frequency with related percentage values were used for expressing variables. Fisher-Freeman-Halton test was used to determine statistical significance of the epidural fibrosis extention, foreign-body reaction, granulation tissue, inflammation, medulla spinalis retraction, dural adhesion, and fibroblast cell density among groups. Statistical analysis was performed with use of the IBM SPSS ver. 20 software (IBM Co., Armonk, NY, USA). Statistical significance was defined as $\alpha=0.05$.

\section{Results}

The final evaluation was done using 48 adult female Sprague-Dawley rats. All the animals were active, ambulatory, and showed no BBB scale neurological deficit at the time of sacrifice. No clinical signs of infection or side effects were encountered in the skin, fascia, and muscle layers. All wounds healed uneventfully after surgery. However, alopecia did develop in some rats in the systemic IFN- $\beta$-1a groups. Significant concordance was achieved between the two observers for all parameters.

Statistically significant differences were evident between groups in terms of medulla spinalis retraction $(p=0.019)$. Various grades of epidural fibrosis were observed in all rats. The sham and control groups had dense epidural fibrosis, while IFN- $\beta$-1a groups had less and varying degrees of epidural fibrosis. Animals treated with local and systemic IFN- $\beta$-1a showed discrete hyposignal space between the dura mater and the surrounding muscle tissue and nevre roots. In the $\mathrm{S}_{44}, \mathrm{~S}_{22}$, and $\mathrm{L}_{44}$ groups, epidural fibrosis was statistically significantly less than sham ( $p=0.001, p=0.001$, and $p=0.014$, respectively) and control groups ( $p=0.001, p=0.001$, and $p=0.010$, respectively).

Inflammation and fibroblast cell density were significantly different among various groups (both $p<0.001$ ). Inflammation and fibroblast cell density were higher in the control and sham groups when compared with the $S_{44}, S_{22}$, $\mathrm{L}_{44}$, and $\mathrm{L}_{22}$ groups (Table 1 ).

Distribution of foreign-body reaction was significantly different among the groups $(p=0.035)$. Foreign-body reaction in the $\mathrm{L}_{44}$ and $\mathrm{L}_{22}$ groups was less than the control group ( $p=0.026$ and $p=0.007$, respectively). Distribution of granulation tissue was also significantly different among groups ( $p=0.018$ ), with less granulation tissue in rats of the $\mathrm{L}_{22}$ group compared with the control and $\mathrm{S}_{22}$ groups ( $p=0.077$ and $p=0.007$, respectively).

Distribution of dural adhesion was significantly different among the groups $(p<0.001)$, and was being significantly less in the $S_{44}, S_{22}, L_{44}$ groups compared with the
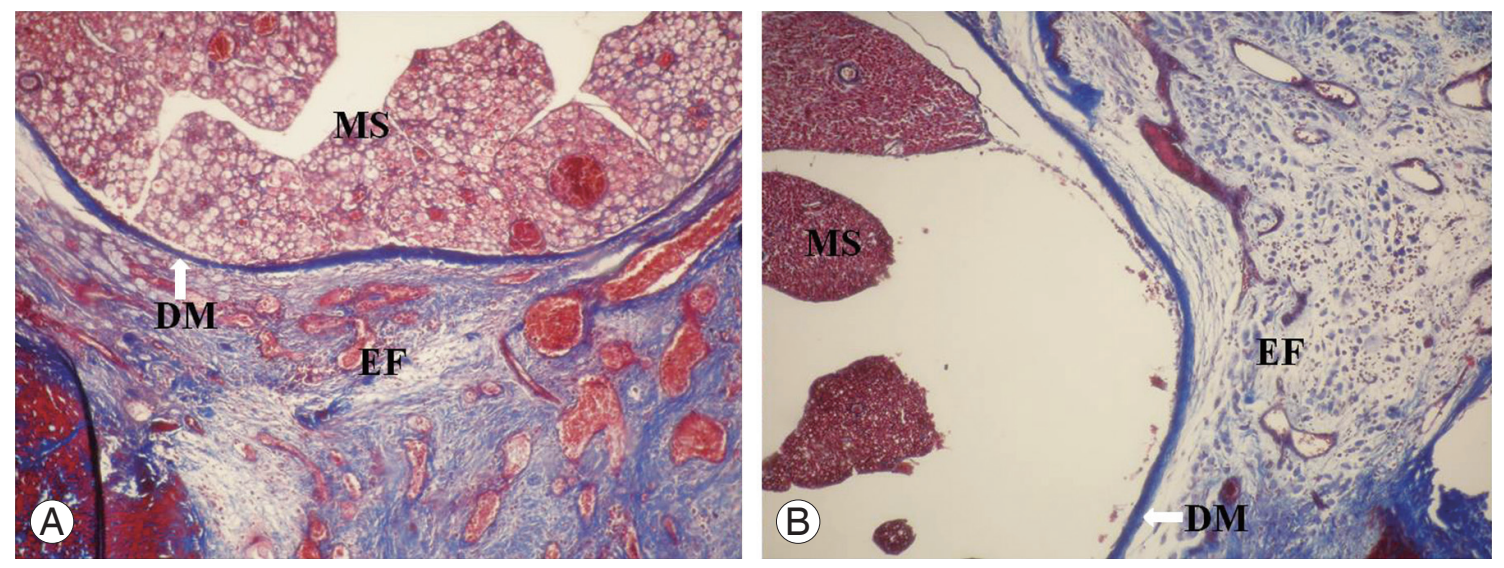

Fig. 1. Epidural fibrosis and dural adhesion in the groups of rats. (A) Grade 3 epidural fibrosis and dural adhesion is shown in the control group stained with Masson-Trichrome $(\mathrm{MT}) \times 100$. Dense epidural fibrosis, dural adhesion, and medulla spinalis retraction are seen in the laminectomized area. (B) Grade 1 epidural fibrosis and dural adhesion is shown in the $\mathrm{S}_{44}$ group stained with $M T \times 100$. Note that less epidural fibrosis, fibroblast cell density, and only thin fibrous bands between dura mater and scar tissue are observed in the laminectomized area. DM, dura mater (white arrow); EF, epidural fibrosis; MS, medulla spinalis. 
Table 1. Results of histopathologic evaluation

\begin{tabular}{|c|c|c|c|c|c|c|}
\hline Variable & $S_{44}(n=8)$ & $S_{22}(n=8)$ & $\mathrm{L}_{44}(\mathrm{n}=8)$ & $\mathrm{L}_{22}(\mathrm{n}=8)$ & Sham $(n=8)$ & Saline $(n=8)$ \\
\hline \multicolumn{7}{|c|}{ Multiple sclerosis retraction } \\
\hline Absent & $7(87.5)$ & $8(100.0)$ & $8(100.0)$ & $8(100.0)$ & $5(62.5)$ & $4(50.0)$ \\
\hline Mild & $1(12.5)$ & 0 & 0 & 0 & $3(37.5)$ & $4(50.0)$ \\
\hline Moderate & 0 & 0 & 0 & 0 & 0 & 0 \\
\hline Severe & 0 & 0 & 0 & 0 & 0 & 0 \\
\hline \multicolumn{7}{|c|}{ Epidural fibrosis } \\
\hline Absent & 0 & $1(12.5)$ & 0 & 0 & 0 & 0 \\
\hline Mild & $8(100.0)$ & $7(87.5)$ & $7(87.5)$ & $5(62.5)$ & $1(12.5)$ & $1(12.5)$ \\
\hline Moderate & 0 & 0 & $1(12.5)$ & $3(37.5)$ & $5(62.5)$ & $7(87.5)$ \\
\hline Severe & 0 & 0 & 0 & 0 & $2(25.0)$ & 0 \\
\hline \multicolumn{7}{|l|}{ Inflammation } \\
\hline Exist & $7(87.5)$ & $8(100.0)$ & $8(100.0)$ & $7(87.5)$ & $3(37.5)$ & $2(25.0)$ \\
\hline No & $1(12.5)$ & 0 & 0 & $1(12.5)$ & $5(62.5)$ & $6(75.0)$ \\
\hline \multicolumn{7}{|c|}{ Foreign body reaction } \\
\hline Absent & $2(25.0)$ & $2(25.0)$ & $4(50.0)$ & $5(62.5)$ & $1(12.5)$ & 0 \\
\hline Mild & $6(75.0)$ & $5(62.5)$ & $3(37.5)$ & $2(25.0)$ & $7(87.5)$ & $8(100.0)$ \\
\hline Moderate & 0 & $1(12.5)$ & $1(12.5)$ & $1(12.5)$ & 0 & 0 \\
\hline Severe & 0 & 0 & 0 & 0 & 0 & 0 \\
\hline \multicolumn{7}{|c|}{ Dural adhesion } \\
\hline 0 & $5(62.5)$ & $8(100.0)$ & $5(62.5)$ & 0 & $3(37.5)$ & 0 \\
\hline 1 & $3(37.5)$ & 0 & $2(25.0)$ & $8(100.0)$ & $1(12.5)$ & $1(12.5)$ \\
\hline 2 & 0 & 0 & $1(12.5)$ & 0 & $1(12.5)$ & $1(12.5)$ \\
\hline 3 & 0 & 0 & 0 & 0 & $3(37.5)$ & $6(75.0)$ \\
\hline \multicolumn{7}{|c|}{ Granulation tissue } \\
\hline Exist & $1(12.5)$ & $2(25.0)$ & $1(12.5)$ & $4(50.0)$ & $8(100.0)$ & $2(25.0)$ \\
\hline No & $7(87.5)$ & $6(75.0)$ & $7(87.5)$ & $4(50.0)$ & 0 & $6(75.0)$ \\
\hline \multicolumn{7}{|c|}{ Fibroblast cell density } \\
\hline$<100$ & $7(87.5)$ & $8(100.0)$ & $8(100.0)$ & $7(87.5)$ & 0 & $1(12.5)$ \\
\hline $100-150$ & $1(12.5)$ & 0 & 0 & $1(12.5)$ & $5(62.5)$ & $4(50.0)$ \\
\hline$>150$ & 0 & 0 & 0 & 0 & $3(37.5)$ & $3(37.5)$ \\
\hline
\end{tabular}

Dural adhesions was graded on the basis of the scheme devised by He et al. [18]: grade 0, the dura is free of scar tissue; grade 1, thin fibrous bands are observed between the scar tissue and dura; grade 2, continuous adherence is observed in less than two-thirds of the laminectomy defect; and grade 3, scar tissue adherence is large, affecting more than two-thirds of the laminectomy defect, or the adherence extends to the nerve roots. The fibroblast and inflammatory cell densities were graded as follows: grade 1, less than 100 fibroblasts/ inflammatory cells per 400x field; grade 2, 100 to 150 fibroblasts/inflammatory cells per 400x field; grade 3, more than 150 fibroblasts/inflammatory cells per 400x field.

$\mathrm{L}_{22}$ group $(p=0.026, p<0.001$, and $p=0.007$, respectively) (Table 2).

\section{Discussion}

Epidural fibrosis is an inevitable consequence of spinal laminectomy and one of the causative factors in failed back syndrome after spinal surgery. Fibrosis tissue can cause adhesions among adjacent tissues; dense fibrotic tissue can lead to compression on adjacent anatomical structures, dural tethering, immobility, and distortion on the spinal nerve root, resulting in susceptibility of the spinal root. However, there is no consensus for the role of epidural fibrosis in lingering back pain or its efficacy on 
Table 2. Intergroup comparisons of parameters followed by overall comparisons as $p$-values

\begin{tabular}{|c|c|c|c|c|c|c|c|}
\hline Groups & $\begin{array}{l}\text { MS retraction } \\
\qquad(p=0.019)\end{array}$ & $\begin{array}{l}\text { Epidural } \\
\text { fibrosis } \\
(p<0.001)\end{array}$ & $\begin{array}{l}\text { Inflammation } \\
(p<0.001)\end{array}$ & $\begin{array}{l}\text { Foreign-body } \\
\text { reaction } \\
(p=0.035)\end{array}$ & $\begin{array}{c}\text { Dural } \\
\text { adhesion } \\
(p<0.001)\end{array}$ & $\begin{array}{c}\text { Granulation } \\
\text { tissue } \\
(p=0.018)\end{array}$ & $\begin{array}{c}\text { Fibroblast } \\
\text { cell density } \\
(p<0.001)\end{array}$ \\
\hline$S_{44}-S_{22}$ & 1.000 & 1.000 & 1.000 & 1.000 & 0.200 & 1.000 & 1.000 \\
\hline $\mathrm{S}_{44}-\mathrm{L}_{44}$ & 1.000 & 1.000 & 1.000 & 0.315 & 1.000 & 1.000 & 1.000 \\
\hline $\mathrm{S}_{44}-\mathrm{L} 22$ & 1.000 & 1.000 & 1.000 & 0.132 & 0.026 & 0.282 & 1.000 \\
\hline $\mathrm{S}_{44}-$ Sham & 0.041 & 0.001 & 0.119 & 1.000 & 0.160 & 0.041 & 0.001 \\
\hline $\mathrm{S}_{44}-$ control & 0.119 & 0.001 & 0.041 & 0.467 & 0.001 & 0.001 & 0.010 \\
\hline $\mathrm{S}_{22}-\mathrm{L}_{44}$ & NP & 1.000 & NP & 0.782 & 0.200 & 1.000 & NP \\
\hline$S_{22}-L_{22}$ & 1.000 & 0.200 & 1.000 & 0.429 & $<0.001$ & 0.608 & 1.000 \\
\hline $\mathrm{S}_{22}-$ Sham & 0.007 & 0.001 & 0.026 & 0.569 & 0.026 & 0.132 & $<0.001$ \\
\hline $\mathrm{S}_{22}-$ control & 0.026 & 0.001 & 0.007 & 0.200 & $<0.001$ & 0.007 & 0.001 \\
\hline $\mathrm{L}_{44}-\mathrm{L}_{22}$ & 1.000 & 0.569 & 1.000 & 1.000 & 0.007 & 0.282 & 1.000 \\
\hline $\mathrm{L}_{44}$-Sham & 0.007 & 0.014 & 0.026 & 0.119 & 0.393 & 0.041 & $<0.001$ \\
\hline $\mathrm{L}_{44}$-control & 0.026 & 0.010 & 0.007 & 0.026 & 0.002 & 0.001 & 0.001 \\
\hline $\mathrm{L}_{22}$-Sham & 0.041 & 0.119 & 0.026 & 0.041 & 0.001 & 0.608 & 0.001 \\
\hline $\mathrm{L}_{22}$-control & 0.119 & 0.119 & 0.007 & 0.007 & 0.001 & 0.077 & 0.010 \\
\hline Sham-control & 1.000 & 0.713 & 1.000 & 1.000 & 0.256 & 0.467 & 1.000 \\
\hline
\end{tabular}

Values in boldface are statistically significant.

MS, multiple sclerosis; NP, not performed: analyses could not be performed due to insufficient sample size.

bad clinical outcomes, but it can cause difficulty for reexposure of operative areas during second surgery that may lead to complications [27].

Multiple factors are involved in the pathogenesis of epidural fibrosis formation. These include individual variability, postoperative haematoma, laminectomy techniques, amount of bone removed, and species and race differences [28]. In our study, laminectomy and discectomy (annular fenestration) performed on male Sprague-Dawley rats 12-weeks-of-age and 250-300 g in body weight was done to provide relevance with other studies [29].

Animal and clinical studies have sought to prevent epidural fibrosis $[2,4]$. Although significant results have been reported in a number of studies, peridural fibrosis remains a substantial problem in spinal surgery [1]. Most of these studies are expensive, and the findings are unsuitable for human use.

Fibrogenic pathologies are a characteristic feature of a systemic disease. Generation of specific cytokine patterns by immune and structural cells, and interactions among these cells mediate many of the key events involved in fibrogenesis [1]. The imbalance between Type 1 Type 2 cytokine responses that cues an abnormal response to the injury is an important hypothesis of the pathogenesis of fibrogenesis [1].

The observed pathologies with regard to epidural fibrosis suggest the onset of inflammatory processes after the surgery. IFNs are proteins that are made in and released by host cells in response to the presence of pathogens that include viruses, bacteria, and parasites, and tumor cells. They allow for communication between cells to trigger the protective defenses of the immune system, activate immune cells including natural killer cells and macrophages, and increase recognition of infection or tumor cells by upregulating antigen presentation to T-lymphocytes.

The immunomodulatory effects of IFN- $\beta$ were studied in detail in MS and EAE [22]. IFN- $\beta$ diminishes inflammatory infiltration within the CNS [22]. IFN- $\beta-1 \mathrm{a}$ is a glycoprotein produced in mammalian cells using the natural human gene sequence. In an experimental model, the histopathological analysis of the spinal cord after IFN$\beta$-1a immunization revealed a significantly lower MS lesion load in comparison with vehicle treated controls [22]. Topical application of low-dose IFN-gamma $(\gamma)$ is an effective and safe method of preventing peridural fibrosis [1]. 
The T-cellular immunomodulatory effects of IFN- $\beta$ are mediated by antagonizing the pro-inflammatory properties of IFN- $\gamma$ secreted by CD4-positive T-helper cells [28], and inhibition of T-cell proliferation [30]. Despite the widespread use and well documented immuomodulator effects of IFN- $\beta$-1a no published study has investigated its efficacy on epidural fibrosis.

Compared to the sham and control groups, epidural fibrosis, dural adhesion formation, inflammation, and fibroblast cell density were statistically less in the $\mathrm{S}_{44}$ and $\mathrm{L}_{44}$ groups, demonstrating that the systemic or local use of IFN- $\beta$-1a may prevent epidural fibrosis formation after spinal surgery. There were no statistical differences between $\mathrm{S}_{44}$ and $\mathrm{L}_{44}$ groups, allowing us to conclude that we can use IFN- $\beta-1$ locally or systemically to prevent epidural fibrosis.

Fibroblast cell density was significantly less in all IFN$\beta$-1a groups compared to sham and control groups, proving that IFN- $\beta-1 \mathrm{a}$ is an effective medication to prevent migration of fibroblasts. Fibrosis tissue will have alooser conformation.

\section{Conclusions}

Local or systemic use of $44 \mu \mathrm{g}$ IFN- $\beta-1$ is an effective and promising material in prevention of epidural fibrosis and reduction of fibrotic tissue density. However, the efficacy of this agent should also be supported with further experimental and clinical studies.

\section{Conflict of Interest}

No potential conflict of interest relevant to this article was reported.

\section{Acknowledgments}

This study is granted by Uludag University Scientific Project Found.

\section{References}

1. Emmez H, Kardes O, Dogulu F, Kurt G, Memis L, Baykaner MK. Role of antifibrotic cytokine interferon-gamma in the prevention of postlaminectomy peridural fibrosis in rats. Neurosurgery 2008;62:13517.
2. Barbera J, Gonzalez J, Esquerdo J, Broseta J, BarciaSalorio JL. Prophylaxis of the laminectomy membrane: an experimental study in dogs. J Neurosurg 1978;49:419-24.

3. Boot DA, Hughes SP. The prevention of adhesions after laminectomy: adverse results of Zenoderm implantations into laminectomy sites in rabbits. Clin Orthop Relat Res 1987;(215):296-302.

4. Ozer AF, Oktenoglu T, Sasani M, et al. Preserving the ligamentum flavum in lumbar discectomy: a new technique that prevents scar tissue formation in the first 6 months postsurgery. Neurosurgery 2006;59: ONS126-33.

5. Park YK, Tator $\mathrm{CH}$. Prevention of arachnoiditis and postoperative tethering of the spinal cord with GoreTex surgical membrane: an experimental study with rats. Neurosurgery 1998;42:813-23.

6. Choi HJ, Kim KB, Kwon YM. Effect of amniotic membrane to reduce postlaminectomy epidural adhesion on a rat model. J Korean Neurosurg Soc 2011; 49:323-8.

7. Jacobs RR, McClain O, Neff J. Control of postlaminectomy scar formation: an experimental and clinical study. Spine (Phila Pa 1976) 1980;5:223-9.

8. Dogulu F, Durdag E, Cemil B, Kurt G, Ozgun G. The role of FloSeal in reducing epidural fibrosis in a rat laminectomy model. Neurol Neurochir Pol 2009;43:346-51.

9. Songer MN, Rauschning W, Carson EW, Pandit SM. Analysis of peridural scar formation and its prevention after lumbar laminotomy and discectomy in dogs. Spine (Phila Pa 1976) 1995;20:571-80.

10. diZerega GS, Cortese $S$, Rodgers KE, et al. A modern biomaterial for adhesion prevention. J Biomed Mater Res B Appl Biomater 2007;81:239-50.

11. Dogan S, Taskapilioglu O, Sahin S, Korfali E. The effects of seprafilm and interceed TC7 on epidural fibrosis in a rat hemilaminectomy model. Neurosurg Q 2009;19:190-5.

12. Rodgers KE, Robertson JT, Espinoza T, et al. Reduction of epidural fibrosis in lumbar surgery with Oxiplex adhesion barriers of carboxymethylcellulose and polyethylene oxide. Spine J 2003;3:277-83.

13. Kato T, Haro H, Komori H, Shinomiya K. Evaluation of hyaluronic acid sheet for the prevention of postlaminectomy adhesions. Spine J 2005;5:479-88.

14. Akeson WH, Massie JB, Huang B, et al. Topical high- 
molecular-weight hyaluronan and a roofing barrier sheet equally inhibit postlaminectomy fibrosis. Spine J 2005;5:180-90.

15. Massie JB, Schimizzi AL, Huang B, Kim CW, Garfin SR, Akeson WH. Topical high molecular weight hyaluronan reduces radicular pain post laminectomy in a rat model. Spine J 2005;5:494-502.

16. Cekinmez M, Sen O, Atalay B, et al. Effects of methyl prednisolone acetate, fibrin glue and combination of methyl prednisolone acetate and fibrin glue in prevention of epidural fibrosis in a rat model. Neurol Res 2010;32:700-5.

17. Foulkes GD, Robinson JS Jr. Intraoperative dexamethasone irrigation in lumbar microdiskectomy. Clin Orthop Relat Res 1990;(261):224-8.

18. He Y, Revel M, Loty B. A quantitative model of postlaminectomy scar formation: effects of a nonsteroidal anti-inflammatory drug. Spine (Phila Pa 1976) 1995;20:557-63.

19. Pospiech J, Pajonk F, Stolke D. Epidural scar tissue formation after spinal surgery: an experimental study. Eur Spine J 1995;4:213-9.

20. Colak A, Bavbek M, Aydin NE, Renda N, Acikgoz B. Effect of CO2 laser on spinal epidural fibrosis. Acta Neurochir (Wien) 1996;138:162-6.

21. Gerszten PC, Moossy JJ, Flickinger JC, Gerszten $\mathrm{K}$, Kalend A, Martinez AJ. Inhibition of peridural fibrosis after laminectomy using low-dose external beam radiation in a dog model. Neurosurgery 2000; 46:1478-85.

22. Sattler MB, Demmer I, Williams SK, et al. Effects of interferon-beta-1a on neuronal survival under autoimmune inflammatory conditions. Exp Neurol 2006;
201:172-81.

23. Basso DM, Beattie MS, Bresnahan JC. A sensitive and reliable locomotor rating scale for open field testing in rats. J Neurotrauma 1995;12:1-21.

24. Basso DM, Beattie MS, Bresnahan JC. Graded histological and locomotor outcomes after spinal cord contusion using the NYU weight-drop device versus transection. Exp Neurol 1996;139:244-56.

25. Topsakal C, Akpolat N, Erol FS, et al. Seprafilm superior to Gore-Tex in the prevention of peridural fibrosis. J Neurosurg 2004;101:295-302.

26. Hinton JL Jr, Warejcka DJ, Mei Y, et al. Inhibition of epidural scar formation after lumbar laminectomy in the rat. Spine (Phila Pa 1976) 1995;20:564-70.

27. Davis RA. A long-term outcome analysis of 984 surgically treated herniated lumbar discs. J Neurosurg 1994;80:415-21.

28. Yoshida R, Murray HW, Nathan CF. Agonist and antagonist effects of interferon alpha and beta on activation of human macrophages: two classes of interferon gamma receptors and blockade of the highaffinity sites by interferon alpha or beta. J Exp Med 1988; 167:1171-85.

29. Kasimcan MO, Bakar B, Aktas S, Alhan A, Yilmaz M. Effectiveness of the biophysical barriers on the peridural fibrosis of a postlaminectomy rat model: an experimental research. Injury 2011;42:778-81.

30. Schmidt J, Sturzebecher S, Toyka KV, Gold R. Interferon-beta treatment of experimental autoimmune encephalomyelitis leads to rapid nonapoptotic termination of $\mathrm{T}$ cell infiltration. J Neurosci Res 2001;65:59-67. 